\title{
Valve of Kerckring
}

National Cancer Institute

\section{Source}

National Cancer Institute. Valve of Kerckring. NCI Thesaurus. Code C33850.

Circularly arranged folds of the mucosa and submucosa of the small intestine, which extend into the lumen, and which function to increase the absorptive surface area. They are most prominent in the jejunum and proximal ileum, and are generally absent in the proximal duodenum and distal ileum. 